\title{
Design, Construction, and Analysis of Specific Zinc Finger Nucleases for microphthalmia - associate transcription factor
}

\author{
Wenwen Wang, Hongmao Liu, Haibin Zhao, Zaili Luo and Yongxiang Shi* \\ Shandong Provincial Key Laboratory of Animal Cells and Developmental Biology; School of Life Science; \\ Shandong University; Jinan; 250100; China
}

\begin{abstract}
This work studied the design, construction, and cleavage analysis of zinc finger nucleases (ZFNs) that could cut the specific sequences within microphthalmia - associate transcription factor (mitfa) of zebra fish. The target site and ZFPs were selected and designed with zinc finger tools, while the ZFPs were synthesized using DNAWorks and twostep PCR. The ZFNs were constructed, expressed, purified, and analyzed in vitro. As expected, the designed ZFNs could create a double-stand break (DSB) at the target site in vitro. The DNAWorks, two-step PCR, and an optimized process of protein expression were firstly induced in the construction of ZFNs successfully, which was an effective and simplified protocol. These results could be useful for further application of ZFNs-mediated gene targeting.
\end{abstract}

Key words: Zinc finger nuclease, DNAWorks, gene synthesis, gene knockout

\section{INTRODUCTION}

Reverse genetics has been a focus in the fields of gene functions and diseases' gene therapy. However, the reverse genetics techniques of nonmammalian vertebrates and plants are limited to Morpholinos (MO), RNAi and TILLING. Performed in the early period of embryonic development, morpholinos have no effect on genome (Sumanas 2002). Heritable mutants can't be obtained by RNAi technology either. (Hannon 2002). Although heritable mutants can be obtained by TILLING, TILLING technology is noneffective and time-consuming for genes containing many introns (Sessions 2002).

Gene targeting using the homologous recombination has performed well in embryonic stem cell lines of mouse. However, targeted genomic manipulation has failed in other nonmammalian vertebrates (Deiters 2006).

Zinc finger nuclease (ZFN) has become a new tool for gene knockout in other metazoan, plants and even human cell lines. ZFNs are engineering restriction endonucleases, which can be used to cut the DNA sequence and create double-stranded breaks (DSBs) at target points in the chromosomes. Most DSBs in genome may be repaired by the homologous recombination (HR). While some DSBs of the damaged chromosomes can be repaired by non-homologous ending joining (NHEJ), small deletions or insertions were followed by ligations. Hence, the mutants with site-specific manipulation could be obtained through NHEJ.

ZFNs are fusion proteins composed of DNAbinding domains and non-specific cleavage domains consisting of the cleavage domain of wild type restriction enzyme Fok I (WT Fok). The WT Fok I was discovered in Flavobacterium okeanokoites, which was a member of type IIS restriction endonucleases. The WT Fok I is also made up of a cleavage domain and a DNA recognition domain. The recognition domain of

\footnotetext{
"Author for correspondence: shiyx@ @sdu.edu.cn
} 
WT Fok I binds to the sequence 5'-GGATG-3' (Sugisaki, 1981), while the cleavage domains form a dimmer to cut DNA sequences. The cleavage domains of WT Fok I constitute the cleavage domains of ZFNs, which are more active in form of heterodimers. Thus, ZFNs form heterodimers to induce the DSB at target points in chromosomes (Bibikova, 2001).

Another domain of ZFNs is the DNA-binding domain, which is zinc finger protein consisting of several $\mathrm{C}_{2} \mathrm{H}_{2}$ zinc finger (ZF) motifs. Each ZF motif comprises 30 amino acids, and contains a $\alpha$ helix and two $\beta$-sheets. A ZF motif binds to a triplet of DNA sequence by crucial amino acids at the positions -1, 2, 3 and 6 of $\alpha$-helix (Erickson, 1999). Thus, different ZF motifs may be designed by changing these crucial amino acids to recognize different triplets of DNA sequence, while the other amino acids can be maintained as an unalterable backbone (Wolfe 1999). Each ZF motif binds to a triplet, while ZFP consists of consecutive ZF motifs recognizing consecutive triplets. ZFs recognizing 64 possible triplets have been detected and isolated with phage display (Segal 1999; Liu 2002). Thus, ZFPs and ZFNs can be designed to bind and cleave arbitrarily chosen sequences in principle. The interests of ZFNs application have been stimulated in the fields of gene knockout and gene replacement at target sites in the genome of many model organism, including Xenopus laevis (Bibikova 2001), plant cells (Lloyd 2005), Drosophila (Bibikova 2002), Caenorhabditis elegans (Morton 2006), Danio rerio (Doyon 2008) and even human cells (Porteus 2003).

The DNA-binding domain of ZFNs contains several ZF motifs whose number can be changed. Three ZF motifs are believed to be the minimum to achieve the adequate specificity and affinity. Although adding more ZF motifs may enhance the binding specificity, it also increases the difficulty of ZFP gene synthesis and searching for an appropriate site. Three or four ZF motifs have been used wildly and successfully for strictly cleavage in genome (Bibikova 2002; Porteus 2006).

The wildly application of ZFNs can be imagined, due to the targeted gene manipulation in nonmammalian vertebrates. Microphthalmiaassociate transcription factor (mitf), a member of basic helix-loop-helix zipper proteins, regulates the specific gene expression and signal transmission of melanocytes. Mitf, a kind of conservative gene in evolution, encodes five protein isoforms, including MITF-A, MITF-B, MITF-C, MITF-H, and MITF-M. It encodes two isoform proteins, MITF-A and MITF-B, in zebra fish (Shibahara 2001). The mitfa was chosen as the target gene for constructing the specific ZFNs in this work to establish the basis for gene function research and human disease models' construction. This work studied the construction protocol of ZFNs for target site, in which DNAWorks was induced to design the coding sequences of ZFPs. Then a simplified method of gene synthesis, a twostep gene synthesis method, was carried out successfully using DNAWorks software.

\section{MATERIALS AND METHODS}

\section{Search for ZFN target sites}

The DNA sequence and cDNA sequence of mitfa were found at NCBI website. When these sequences are put into the website of zinc finger tools (http://www.scripps.edu/mb/barbas/ zfdesign/ zfdesignhome.php), several parameters should be chosen, such as "separated target sites", "the core sequence" and "triplets to search" (Mandell 2006). Then all the target sites on the DNA sequence are output. According to the scores of the website, the conserved sites of the DNA sequences and the difficulty of gene synthesis, the DNA segment "tttgactcttatcaaagacctgat" between 2965bp and $2988 \mathrm{bp}$ of mitfa was chosen as a plausible target site.

\section{Design of the coding sequences of ZFPs}

While the target site was output, the amino acid sequences of ZFP1 and ZFP2 were also obtained with zinc finger tools. To design the coding sequence of ZFPs, their amino acid sequences were input into the website of DNAWorks (http://helixweb.nih.gov/dna-works/). While several parameters needed to be defined, including codon optimization, codon frequencies, melting temperature and hairpins formation (Hoover 2002). Firstly, the codon usage table of Zebra fish was found in the codon usage database and input into DNAWorks. Secondly, the melting temperature was limited to $60^{\circ} \mathrm{C}$. Thirdly, the hairpin formation was avoided in the coding sequences of ZFPs. Finally, the website of DNAWorks output the coding sequences of ZFPs and fourteen oligonucleotides sequences for gene synthesis of each ZFP. 


\section{Construction of ZFPs' coding sequences}

To construct the coding sequences of ZFPs, the two-step PCR method, overlap extension (OE) PCR and amplification PCR, was used for gene synthesis according to Dong et al (Dong, 2007). Fourteen oligonucleotides were mixed and diluted to $2 \mu \mathrm{M}$ with $\mathrm{ddH}_{2} \mathrm{O}$, which were used as the primer mixture in the PCR for synthesizing gene. The fist-step PCR, OE PCR, was carried out in a $50 \mu \mathrm{l}$ reaction mixture including $4 \mu \mathrm{l}$ oligonucleotides mixture, $250 \mu \mathrm{M}$ dNTP, $1 \times$ PCR buffer, and $0.25 \mathrm{U}$ of TransStart Fastpfu DNA polymerase (Beijing TransGen Biotech Co., lid.). The OE PCR process consisted of 30 cycles at $95{ }^{\circ} \mathrm{C}$ for $30 \mathrm{~s}, 64{ }^{\circ} \mathrm{C}$ for $60 \mathrm{~s}$, and $72{ }^{\circ} \mathrm{C}$ for $60 \mathrm{~s}$. Then $1.5 \mu$ l of the OE PCR product was added into the amplification PCR reaction mixture, including $0.4 \mu \mathrm{M}$ outer primers, $250 \mu \mathrm{M}$ dNTP, $1 \times$ PCR buffer, and $0.25 \mathrm{U}$ of TransStart Fastpfu DNA polymerase in a volume of $50 \mu \mathrm{l}$, and the process consisted of 30 cycles at $95^{\circ} \mathrm{C}$ for $30 \mathrm{~s}$,
$66{ }^{\circ} \mathrm{C}$ for $30 \mathrm{~s}$, and $72{ }^{\circ} \mathrm{C}$ for 60 s and finally extension at $72{ }^{\circ} \mathrm{C}$ for $5 \mathrm{~min}$. The final PCR products were detected using agarose gel electrophoresis and purified with Gel purification kit (Beijing TransGen Biotech Co., lid.). The whole sequences were cloned into pUC57 vectors, and subsequently sent to a commercial company (Shanghai Sangon Biotech Co., lid.) to sequence and detect its accuracy.

\section{Assemblage of ZFNs}

To assemble the coding sequences of ZFNs, Fok I (RV) (the two complementary FokI cleavage domain variants named as Fok I (RV) and Fok I (DA)) was amplified from the plasmid pCMVGZFN1-Fok-RV using PCR, while Fok I (DA) was obtained from the plasmid pGK-GZF3-FokDA. The purified DNA sequences of Fok I (RV) and Fok I (DA) were cloned into two pET-30a vectors to form the pET-Fok I (RV)-30a and pETFok I (DA)-30a, respectively (Fig.1).

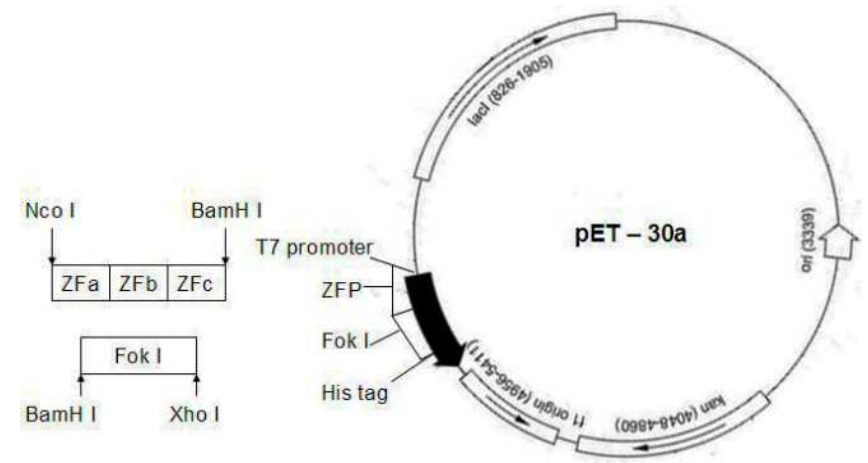

Figure 1 - The construction of ZFNs. †The sequence of FokI and ZFP were linked into the plasmids pET-30a to form pET-ZFN-30a.

The expression vector pET-ZFN1-30a was constructed by linking the ZFP1 sequence into pET-Fok I (RV)-30a. The expression vector pETZFN2-30a was constructed by linking the ZFP2 sequence into pET-Fok I (DV)-30a. Both pETZFN1-30a and pET-ZFN2-30a were amplified in DH5a E. Coli.

\section{Expression and Purification of ZFNs}

To obtain the ZFNs towards mitfa gene in vitro, three steps were carried out including expression, detection, and purification. To express the ZFNs, the vectors pET-ZFN1-30a and pET-ZFN2-30a were transformed into competent DE3 E. coli cells separately, and selected on LB plate containing kanamycin $(10 \mu \mathrm{g} / \mathrm{ml})$ growing at $37^{\circ} \mathrm{C}$ for $12 \mathrm{~h}$.
One positive clone of each vector was cultured at $37^{\circ} \mathrm{C}$ overnight in LB medium containing kanamycin $(10 \mu \mathrm{g} / \mathrm{ml})$ and $\mathrm{ZnCl}_{2}(0.1 \mathrm{mM})$. Then $50 \mathrm{ml}$ culture was added into $1 \mathrm{~L}$ high concentration medium, including $32 \mathrm{~g}$ tryptone, 20 g yeast extract, $5 \mathrm{~g} \mathrm{NaCl}, 2.7 \mathrm{~g} \mathrm{ZnCl}_{2}, 5 \mathrm{mM}$ $\mathrm{NaOH}, 12.54 \mathrm{~g} \mathrm{KHPO}_{4}$, and $2.31 \mathrm{~g} \mathrm{KH}_{2} \mathrm{PO}_{4}$. After growing at $37^{\circ} \mathrm{C}$ for $3 \mathrm{~h}$, the culture mixture was added into $0.3 \mathrm{mM}$ IPTG and shifted to $22^{\circ} \mathrm{C}$ overnight to induce the expression of ZFNs.

To detect the expression of ZFNs, the expression strain cells were collected with centrifuging at $6000 \mathrm{~g}$ for $3 \mathrm{~min}$ from $400 \mu \mathrm{l}$ culture mixture at $4^{\circ} \mathrm{C}$. Then they were re-suspended in protein treatment solution, including $200 \mu 10 \%$ SDS, $200 \mu \mathrm{l}$ beta-mercaptoethanol, and $600 \mu \mathrm{l}$ protein 
loading buffer, treated in water of $100^{\circ} \mathrm{C}$ and subsequently analyzed with SDS-PAGE.

To analyze the expression of soluble ZFNs, DE3 E. coli cells were collected using centrifuging at $6000 \mathrm{~g}$ for $5 \mathrm{~min}$ in $2 \mathrm{ml}$ culture mixture, and resuspended with $2.0 \mathrm{ml} \mathrm{PBS}$ in an ice bath. After the cells in PBS were broken by sonicating in an ice bath, total soluble proteins in the supernatant were collected with centrifuging at $6000 \mathrm{~g}$ for 3 $\min$ at $4^{\circ} \mathrm{C}$. The sediment consisted of total insoluble proteins of the cells. The soluble protein and insoluble protein were analyzed using SDSPAGE respectively.

To purify the ZFNs, total soluble protein of DE3 E. coli cells were collected with ultrasonic wave in an ice bath and purified using Ni-NTA resin (Nanjing genscript Co., Lid.) according to its instruction.

The cleaving activity detection of ZFNs in vitro To detect the cleaving activity of ZFNs, the targeted sequence was linked into a plasmid pEASY-blunt simple as the DNA substrate. If ZFNs cut the targeted sequence in the plasmid, the super-helical conformations of the plasmid would be changed into linear conformation. The change could be detected with agarose gel electrophoresis. The first step was the construction of the DNA substrate (Fig. 2). The DNA substrate sequence (cgcggatcctttgactcttatcaaagacctgataagcttggg)

which contained the targeted sequence of ZFN1 and ZFN2 (tttgactattatcaaagacetgat) was synthesized using PCR with primers Pt1 and Pt2. The sequence of Pt1 was "cgcggatcetttgactcttatcaaagacctg", and that of Pt2 was "cccaagcttatcaggtctttgataagagtcaaagg". The PCR was performed in $30 \mu \mathrm{l}$ reaction mixture, including $0.3 \mu \mathrm{M}$ Pt1, $0.3 \mu \mathrm{M}$ Pt2, $1 \times$ PCR buffer, and $0.25 \mathrm{U}$ of TransStart Fastpfu DNA polymerase, and the process consisted of 35 cycles at $95^{\circ} \mathrm{C}$ for $10 \mathrm{~s}, 54^{\circ} \mathrm{C}$ for $30 \mathrm{~s}$, and $72^{\circ} \mathrm{C}$ for $30 \mathrm{~s}$, and extension at $72{ }^{\circ} \mathrm{C}$ for $10 \mathrm{~min}$. The PCR products of 42 bases were detected using 3\% agarose gel electrophoresis for $10 \mathrm{~min}$. The product bands were cut and purified with Gel purification kit. The targeted sequence was cloned into pEASY-blunt simple, and subsequently sequenced to detect its accuracy. The plasmid pEASY-target-blunt simple was the DNA substrate of the analysis of ZFNs activity in vitro.

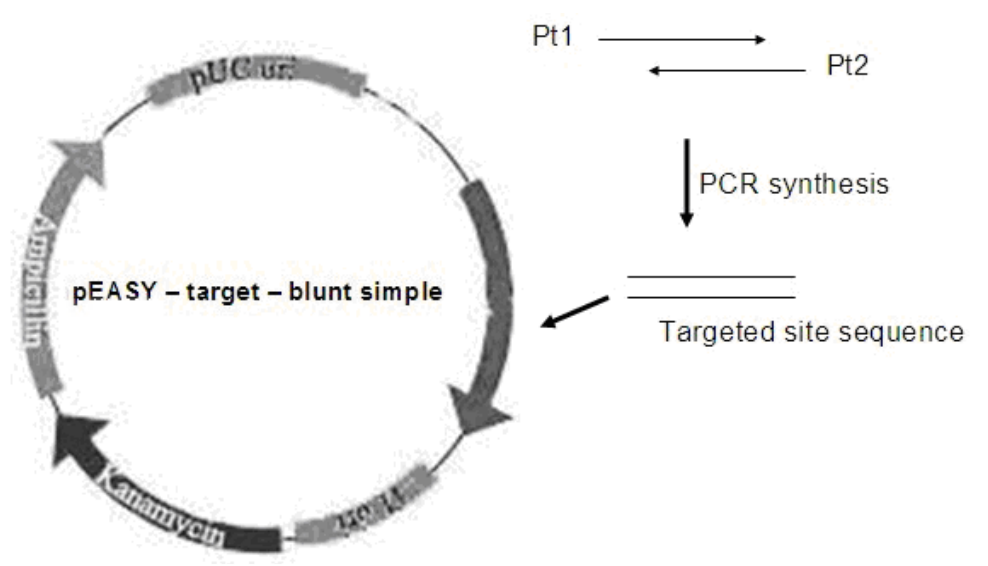

Figure 2 - The construction of pEASY - target - blunt simple.

According to Dana Carroll's report (Carroll, 2006), $20 \mu \mathrm{l}$ reaction mixture consisted of $1 \times \mathrm{ZFN}$ reaction buffer, $50 \mathrm{mM} \mathrm{NaCl}, 1 \mathrm{mM}$ DTT, 100 $\mu \mathrm{g} / \mathrm{ml}$ yeast RNA, $50 \mathrm{ng}$ DNA substrate, and the ZFNs. In the reaction mixture, ZFN1 and ZFN2 were equimolar as well as the DNA substrate. The reaction was started with $1.0 \mu \mathrm{l}$ of $0.2 \mathrm{M} \mathrm{MgCl}_{2}$ at $25^{\circ} \mathrm{C}$ for $1 \mathrm{~h}$. The $\mathrm{ZFN}$ reaction buffer consisted of $0.1 \mathrm{M}$ Tris (pH8.5), $0.5 \mathrm{mM} \mathrm{ZnCl} 2,250 \mu \mathrm{g} / \mathrm{ml}$
BSA. The reaction results were analyzed using agarose gel electrophoresis.

\section{RESULTS}

\section{Targeting site of ZFN}

The DNA and cDNA sequences of mitfa in zebra fish were obtained in NCBI database and 
subsequently input into zinc finger tools to search for the possible sites. According to conservative sites analysis and difficulty analysis of gene synthesis, the sequence between 2965 bp and 2988 bp of mitfa DNA sequence was chosen as targeting site, which was "tttgactcttatcaaagacctgat".

\section{Amino acid sequence of ZFPs}

The reorganization sequences of ZFP1 and ZFP2 are shown in Figure 3. The amino acid sequence of ZFP1 was "LEPGEKPYKCPECG KSFSTSGNLVRHQRTHTGEKPYKCPECGKS FSTKNSLTEHQRTHTGEKPYKCPECGKSFS QLAHLRAHQRTHTGKKTS", and that of ZFP2 was "LEPGEKPYKCPECGKSFSQRANLRAH QRTHTGEKPYKCPECGKSFSDPGALVRHQR THTGEKPYKCPECGKSFSQLAHLRAHQTH TGKKTS”.

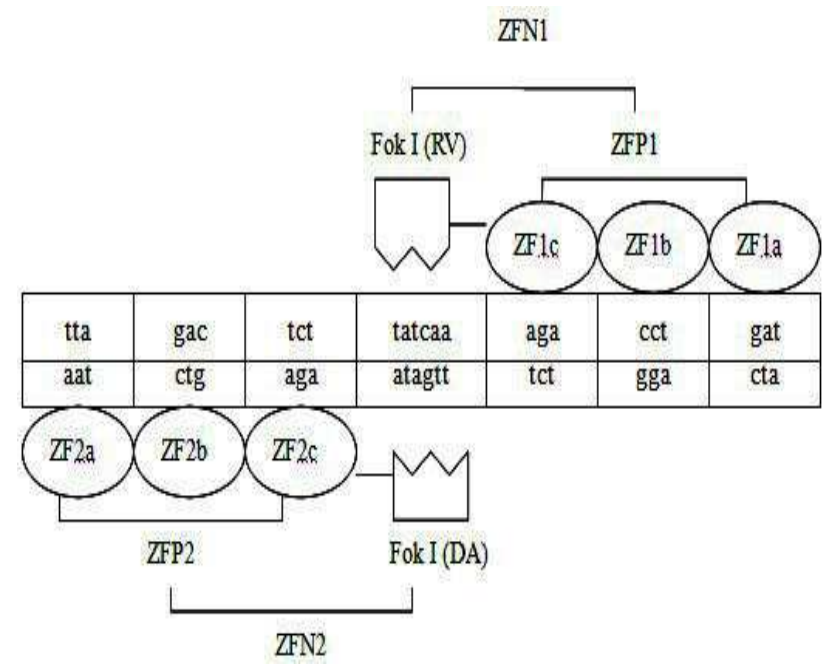

Figure 3 - The reorganization between targeted sequence and ZFNs.

\section{Coding sequences of ZFPs}

After the amino acid sequences of ZFPs were input into DNAWorks, the coding sequences of ZFPs were obtained after condon optimization in DNAWorks. The coding sequence of ZFP1 was "ctggaaccgggcgagaaaccgtacaagtgcccagagtgcggcaa gagcttcagcacctctggtaatctcgtgegccatcagcgtacccacac gggtgaaaaaccttacaaatgtccggagtgtggcaaatcctttccacc aaaaacagcctcaccgaacaccagcgcacccatacgggcgaaaag ccgtataaatgcceggaatgcggtaagtctttctctcagctggcgcatc tgcgtgcccaccaacgtacgcacaccggtaaaaagacctct". The coding sequence of ZFP2 was "ctggaaccgggcgaaaagccttacaaatgcceggagtgcggtaag tctttctcccagcgcgcaaacctcegtgcgcatcagcgcactcacacg ggcgagaaaccatataagtgccctgaatgtggcaaatcctttagcgac ccaggcgegctcgttcgtcaccagcgtacccatacgggtgagaagcc gtacaagtgtccagaatgcggcaagtcctttctcagctggcacatctc cgcgctcaccaacgtacgcataccggcaaaaagacctct".

\section{Oligonucleotides for ZFPs gene synthesis}

The oligonucleotides for ZFPs gene synthesis were obtained using DNAWorks, and synthesized by a commercial company. The oligonucleotides for ZFP1 and ZFP2 are shown in Table 1 and Table 2, respectively.

\section{Gene synthesis of ZFPs}

Two-step PCR was carried out to synthesize the coding sequences of ZFPs, which were detected subsequently using agarose gel electrophoresis (Fig.4). The length of successful PCR products was $276 \mathrm{bp}$. The coding sequences of ZFPs were sequenced analyzed accurately. The two-step PCR and DNAWorks were proved successfully applied in ZFPs gene synthesis. 
Table 1 - The oligonucleotides for ZFP1.

\begin{tabular}{|c|c|}
\hline No. & oligonucleotides \\
\hline 1 & ctggaaccgggcgagaaaccgtacaagtgcccaga \\
\hline 2 & tgaagctcttgccgcactctgggcacttgtacggtt \\
\hline 3 & gtgcggcaagagcttcagcacctctggtaatctcgtg \\
\hline 4 & tgggtacgctgatggcgcacgagattaccagaggtgc \\
\hline 5 & cgccatcagcgtacccacacgggtgaaaaaccttacaa \\
\hline 6 & tgccacactccggacatttgtaaggtttttcacccgtg \\
\hline 7 & atgtccggagtgtggcaaatccttttccaccaaaaacagc \\
\hline 8 & cgctggtgttcggtgaggctgtttttggtggaaaaggatt \\
\hline 9 & ctcaccgaacaccagcgcacccatacgggcgaaaa \\
\hline 10 & ttccgggcatttatacggettttcgccegtatgggtg \\
\hline 11 & gccgtataaatgcccggaatgcggtaagtctttctctcag \\
\hline 12 & cacgcagatgcgecagctgagagaaagacttaccgca \\
\hline 13 & ctggcgcatctgcgtgcccaccaacgtacgcac \\
\hline 14 & agaggtctttttaccggtgtgcgtacgttggtggg \\
\hline
\end{tabular}

Table 2 - The oligonucleotides for ZFP2.

\begin{tabular}{|c|c|}
\hline No. & oligonucleotides \\
\hline 1 & ctggaaccgggcgaaaagccttacaaatgcccggagt \\
\hline 2 & ctgggagaaagacttaccgcactccgggcatttgtaagg \\
\hline 3 & gcggtaagtctttctcccagcgegcaaacctccgtg \\
\hline 4 & gtgagtgcgetgatgcgcacggaggtttgcgcg \\
\hline 5 & cgcatcagcgcactcacacgggcgagaaaccatataag \\
\hline 6 & atttgccacattcagggcacttatatggtttctcgeccgt \\
\hline 7 & tgccetgaatgtggcaaatcctttagcgacccaggcg \\
\hline 8 & ctggtgacgaacgagcgcgectgggtcgctaaagg \\
\hline 9 & cgctcgttcgtcaccagcgtacccatacgggtgaga \\
\hline 10 & tctggacacttgtacggcttctcacccgtatgggtacg \\
\hline 11 & agccgtacaagtgtccagaatgcggcaagtccttttct \\
\hline 12 & cggagatgtgccagctgagaaaaggacttgccgcat \\
\hline 13 & cagctggcacatctccgcgctcaccaacgtacgc \\
\hline 14 & agaggtctttttgccggtatgcgtacgttggtgagcg \\
\hline
\end{tabular}

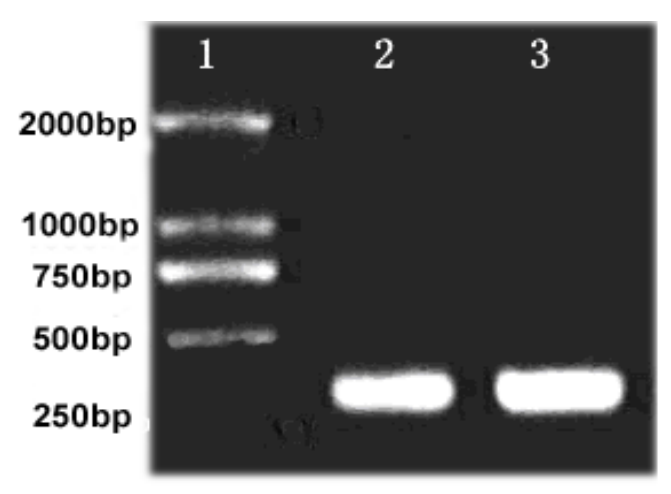

Figure 4 - The PCR products of coding sequences of ZFPs. $\dagger$ Lane 1 contains size standards of DL2000 DNA marker (Beijing Transgene Co., Lid.). Lane 2 is the coding sequence of ZFP1. Lane 3 is the coding sequence of ZFP2. 


\section{Expression vector of ZFNs}

The coding sequence of ZFP1 and FokI (RV) were cloned into pET-30a to form ZFN1 about $900 \mathrm{bp}$, while ZFP2 and FokI (DA) were used to form ZFN2. The results of ZFNs construction were detected using PCR and shown as Figure 5.

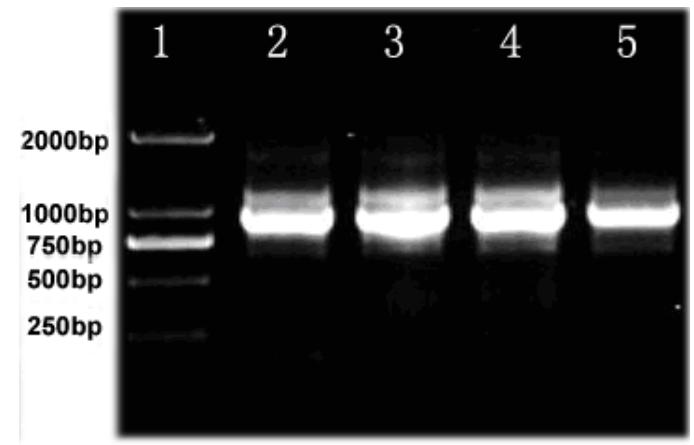

Figure 5 - The PCR results of ZFNs construction. $\dagger$ Lane 1 is the DL2000 DNA marker. Lane 2 and 3 are the coding sequences of ZFN1. Lane 4 and 5 are the coding sequences of ZFN2.

\section{ZFNs protein}

The soluble ZFNs were expressed successfully with $0.3 \mathrm{mM}$ IPTG at $22^{\circ} \mathrm{C}$ in DH5 $\alpha$ E.coli, and purified using $\mathrm{Ni}$ resin (Fig. 6). The targeted proteins of $30 \mathrm{KD}$ were expressed in DH5 $\alpha$ E.coli with IPTG inducement. The soluble proteins were obtained with sonication and centrifugation. The results proved that the protein expression protocol and the high concentration medium were effective to express the soluble ZFNs.

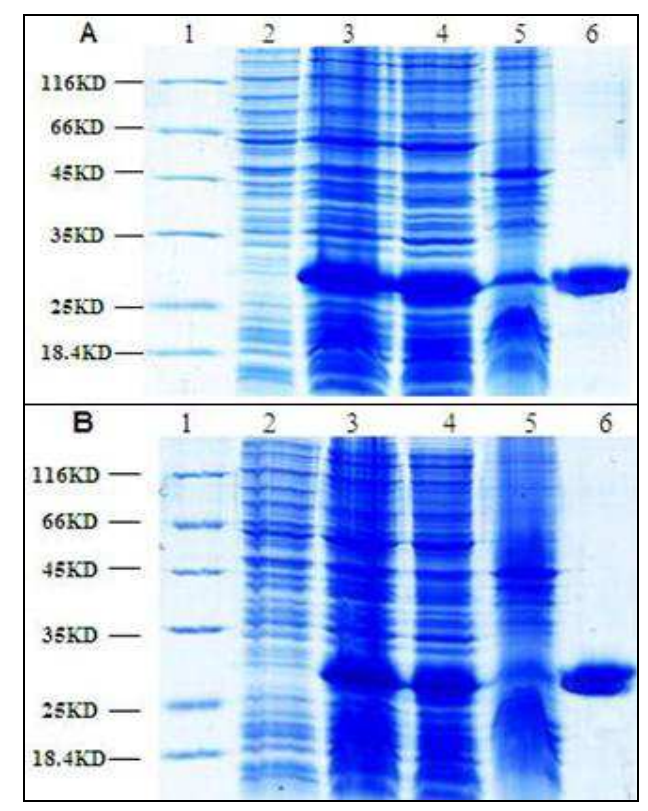

Figure 6 - ZFNs expression detected with SDS-PAGE. $\dagger$ (A) The analysis of ZFN1 expression. (B) The analysis of ZFN2 expression. Lane 1 is the Protein Marker (Fementas Co., Lid.). Lane 2 , the total protein of DH5 $\alpha$ E.coli without IPTG inducement; Lane 3, the total protein with IPTG inducement; Lane 4, the total soluble proteins with IPTG inducement; Lane5, the total insoluble proteins with IPTG inducement; Lane6, purified ZFNs. 


\section{Cleaving activity of ZFNs}

The targeted DNA was linked into pEASY-blunt simple, which were super-helix plasmids. The cleaving activity of ZFNs was detected in vitro and analyzed using agarose gel electrophoresis.
Results in Figure 7 showed that ZFNs could cut the super-helix conformation plasmids into linear molecules at $25^{\circ} \mathrm{C}$ in a reaction mixture with approximately equimolar ZFNs of the DNA substrate.

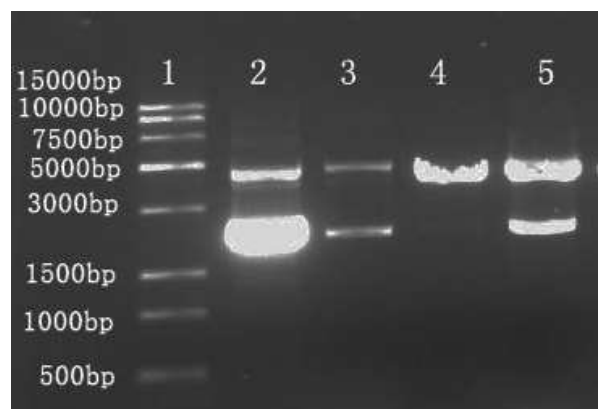

Figure 7 - The cleaving activity of ZFN. †Lane 1 is the DNA marker; lane 2, the control DNA substrate; lane 3 and lane 5, the incomplete cleavage of DNA substrate; lane 4, the complete cleavage of the DNA substrate.

\section{DISCUSSION}

ZFNs are known as effective tools for "directed gene knockout" of the plants and vertebrates as well as human cell lines. Here, the protocol of ZFNs design, engineering and cleaving activity detection has been shown with an example of mitfa (Fig. 8). Several critical factors are involved in the protocols of ZFNs design and engineering. The first factor is the selection of target site in an interested gene. Although many possible sites and relevant ZFPs could be obtained with zinc finger tools, choosing a target site one should pay attention to the following points: (1) To make mutagenesis occur at target site and a unique site should be chosen. (2) Since ZFPs binding all ANN and GNN triplets have been reported detailedly (Liu 2002), target sites consisting of GNN triplets or ANN have priority to be chosen. ZFPs of high binding ability was obtained in this study by choosing a target site, including two GNN and two ANN triplets. (3) The distance between two reorganization sequences in target sites ranged from 4 bp to 6 bp was successful and effective to be cut by ZFNs in vitro (Bibikova 2001). (4) The target sites could be selected considering the critical conservative sites of the gene. The target site chosen was near the critical sites encoding the DNA binding domain of transcription factor mitfa. The second involving factor was that the amino acid sequences of ZFPs which should be converted into coding sequences automatically using the DNA Works software.

The third factor is the gene synthesis of ZFPs. The gene synthesis method used was a reproducible simple method of less error based on DNAWorks (Dong 2007). The genes could be synthesized using two-step PCR, including the overlap extension (OE) PCR and amplification PCR. DNAWorks software was used instead of manual design to obtain the oligonucleotides for gene synthesis, which could keep similar melting temperature of overlapped regions and make sure the specificity of the primers. Several synthesis strategies for target gene could be obtained in DNAWorks. Each synthesis strategy is scored by DNAWorks, and these scores are important parameters for the selection of synthesis strategy. The most critical parameter, overall score, would be zero in an ideal synthesis strategy (Hoover 2002). The two-step PCR is proved a successful method to be used to synthesize ZFP1 and ZFP2.

The fourth factor is the expression of soluble ZFNs. Soluble protein is easier to be extracted, purified, and keep active than the insoluble protein. Protein expression is affected by several factors, including the temperature, concentration of IPTG and medium. Amino acid sequences fold too quickly to form accurate conformation at high temperature and most proteins with inaccurate conformation are insoluble. The expression level of such protein is very low at low temperature. 
The expression temperature used and detected in this work was from 16 to $37^{\circ} \mathrm{C}$, while more soluble ZFNs were expressed at $22^{\circ} \mathrm{C}$, which was induced with IPTG of $0.3 \mathrm{mM}$. The soluble ZFNs were expressed in high concentration medium than Luria-Bertani (LB) medium.

ZFN-mediated gene manipulation becomes an effective tool for gene function studies. Facile constructions and rapid cleavage detections of ZFNs in vitro are essential processes for gene manipulation. This work reported a simple, rapid and reproducible method of less error to design and construct the ZFN. The optimization of ZFPs' coding sequences was simplified with DNAWorks software according to the codon usage frequencies of different organisms. Since the gene synthesis primers with similar melting temperatures were simply obtained using DNAWorks, the coding sequences of ZFPs were successfully carried out using two-step PCR. The facile protocol consisting of design, construction and testing of ZFNs could be widely applied to knock out target gene in the plants, vertebrates and even human cell lines.

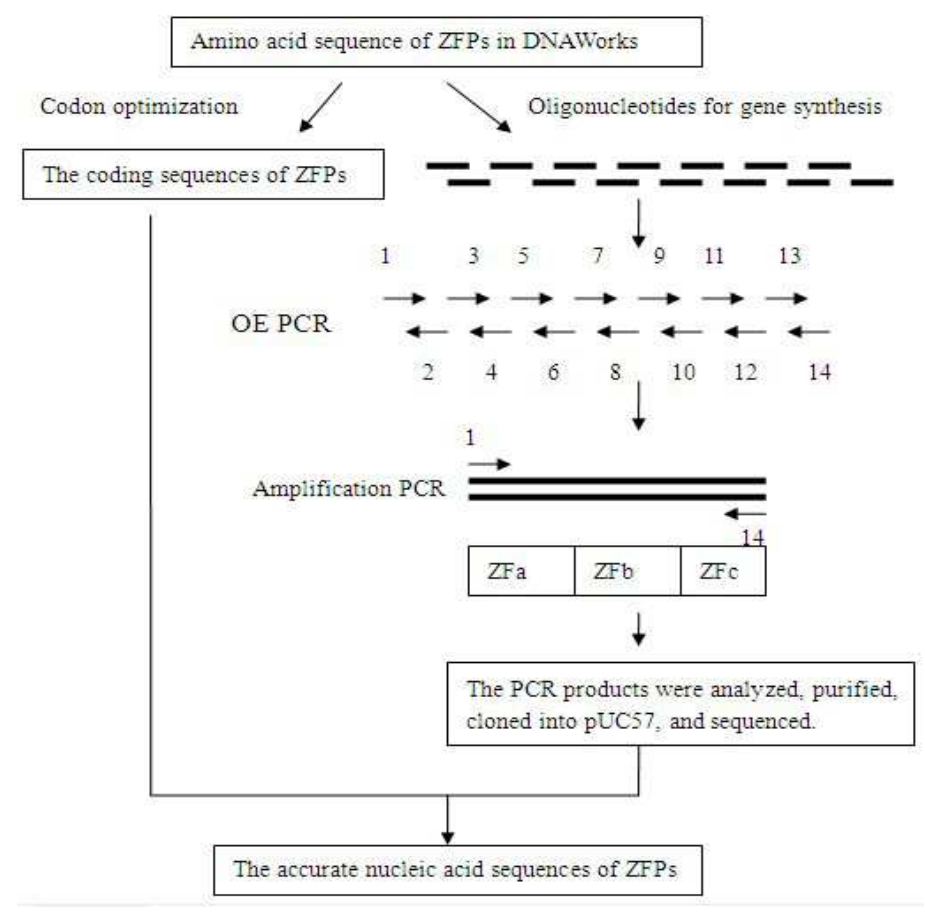

Figure 8 - ZFPs gene synthesis process.

\section{ACKNOWLEDGMENT}

We would like to thank Professor Segal David in the University of California for plasmids pCMVGZFN1-Fok-RV and pGK-GZF3-Fok-DA. This research was supported by Project of IIFSDU2010JC009.

\section{REFERENCE}

Bibikova M, Carroll D, Segal DJ. Stimulation of homologous recombination through targeted cleavage by chimeric nucleases. Mol Cell Biol. 2001; 21: 289697.

Bibikova M, Golic M, Golic KG, Carroll D. Targeted chromosomal cleavage and mutagenesis in Drosophila using zinc-finger nucleases. Genetics. 2002; 161: 1169-1175.

Bibikova M, Beumer K, Trautman JK., Carroll D. Enhancing gene targeting with designed zinc finger nucleases. Science. 2003; 300: 764

Carroll D, Morton JJ, Beumer K.J, Segal DJ, Design, construction and in vitro testing of zinc finger nucleases. Nat Protoc. 2006; 1: 1329-1341.

Deiters A, Yoder JA. Conditional transgene and gene targeting methologies in zebrafish. Zebrafish. 2006; 3: 415-429. 
Dong B, Mao R, Li B, Liu Q, Xu P, Li G. An Improved Method of Gene Synthesis Based on DNAWorks Software and Overlap Extension PCR. Mol Biotechnol. 2007; 37: 195-200.

Doyon Y, McCammon JM, Miller JC, Faraji F, Ngo C, Katibah GE, et al. Heritable targeted gene disruption in zebrafish using designed zinc-finger nucleases. Nat Biotechnol. 2008; 26: 701-708.

Erickson ME, Pabo CO. Contribution of individual side chains to binding affinity and specificity in the Zif268 zinc finger-DNA complex. J Biol Chem. 1999; 274: 19281-19285.

Liu Q, Xia ZQ, Zhong X, Case CC. Validated zinc finger protein designs for all $16 \mathrm{GNN}$ DNA triplet targets. J Biol Chem. 2002; 277: 3850-3856.

Lloyd A, Plaisier CL, Carroll D, Drews GN. Targeted mutagenesis using zinc-finger nucleases in Arabidopsis. PNAS. 2005;102: 2232 - 2237.

Mandell JG, Barbas III CF. Zinc Finger Tools: custom DNA-binding domains for transcription factors and nucleases. Nucleic Acids Res. 2006; 34: 516-523.

Morton J, Davis MW, Jorgensen EM, Carroll D. Induction and repair of zinc-finger nuclease-targeted doublestrand breaks in Caenorhabditis elegans somatic cells. PNAS. 2006; 103: $16370-1637$.

Hannon GJ. RNA interference. Nature. 2002; 418: 244251.

Hoover DM, Kowski JL. DNAWorks: an automated method for designing oligonicleotides for PCR-based gene synthesis. Nucleic Acids Res. 2002; 30: 43.

Porteus MH. Mammalian gene targeting with designed zinc finger nucleases. Mol Ther. 2006; 13: 438-446.
Segal DJ, Dreier B, Beerli RR, Barbas CF. Toward controlling gene expression at will: selection and design of zinc finger domains recognizing each of the 5'-GNN-3' DNA target sequences. PNAS. 1999; 96: 2758-2763.

Sessions A, Burke E, Presting G, Aux G, Elver JM, Patton D, et al. A high throughput Arabidopsis reverse genetics system. Plant Cell. 2002;14: 29852994.

Shibahara S, Takeda K, Yasumoto K, Udono T, Watanabe K, Saito H, et al. MicrophthalmiaAssociated Transcription Factor (MITF):Multiplicity in Structure, Function, and Regulation. J Investig Symp Proc. 2001; 6: 99-104.

Sugisaki H, Kanazawa S. New restriction endonucleases from Flavobacterium okeanokoites (FokI) and Micrococcus luteus (MluI). Gene. 1981; 16: 73-78.

Sumanas S, Larson JD. Morpholino phosphorodiamidate oligonucleotides in zebrafish: A recipe for functional genomics? Brief Funct Genomic Proteomic. 2002; 11: 239-256.

Wolfe SA, Greisman HA, Ramm EI, Pabo CO. Analysis of zinc fingers optimized via phage display: evaluating the utility of a recognition code. $\mathrm{J} \mathrm{Mol}$ Biol. 1999; 285: 1917 - 1934. 